\title{
AE/PE versus crop planning in North-West Alluvial Plain Zone of Bihar
}

\author{
ABDUS SATTAR and S.A. KHAN* \\ Agrometeorology Division, Dr. Rajendra Prasad Central Agricultural University, Pusa, Samastipur, Bihar-848 125 \\ ${ }^{*}$ Department of Agril. Meteorology \& Physics, Bidhan Chandra Krishi Viswavidyalaya, Mohanpur, Nadia, West Bengal-741 125 \\ email:sattar.met@gmail.com
}

\begin{abstract}
The climatic risk for fitting of rainfed crops during kharif and rabi seasons has been worked out by employing the probabilistic values of AE/PE, i.e. index of moisture adequacy $\left(I_{m a}\right)$, estimated at 50 and 75 per cent probability levels on weekly basis for three district (Muzaffarpur, West Champanan and Begusarai of Bihar. Maize followed by toria appeared to be the better cropping system than other cropping systems tested in coarse-textured soil. In medium- and fine-textured soils, maize/short duration rice during kharif season followed by toria in rabi season was found to be the most efficient cropping system for potential productivity under rainfed condition. Kharif maize could successfully replace kharif rice under rainfed condition in areas where moisture stress occurs at different growth phases induced by erratic monsoon. Fair yields of short-duration rice could be expected under rainfed condition in mediumand fine-textured soils. Toria could be more successfully grown as rabi crop than lentil in the three selected locations. The study identifies the phenological phases subjected to water stress and hence, it is effective in scheduling irrigation. Alternate crops have also been suggested.
\end{abstract}

Key words: Water balance, climatic risks, AE, PE, rainfed crop planning, probability

The length of water availability period in a given location varies from year to year and from soil to soil and influences the crop production differently (Ramana Rao et al., 1979a). Rainfed agriculture is besieged by a plethora of risks due to uncertainty of rainfall and recurring drought (Misra, 2005). Thus, crop production under rainfed condition requires intervention of agro-climatic measures to slice down the climatic risks. Hence, precise evaluation of water availability period is an important pre-requisite for crop planning under rainfed condition. The assessment of agroclimatic potential and climatic risk at micro level needs urgent attention for resource allocation and management of rainfed agricultural system more efficiently. In both low and high rainfall regions, crop production under rainfed condition is always fraught with risks because of uneven distribution of rainfall which hinders the farmers from getting potential yields. The evaluation of risks in fitting of crops, based on probabilities of water availability in terms of the ratio of actual evapotranspiration (AE) to potential evapotranspiration ( $\mathrm{PE}$ ), compared to demand of crops has been recognized as a rational approach of practical utility to identify appropriate crops under rainfed condition in a region (Virmani, 1975; Ramana Rao et al., 1979b). The AE values estimated through the water balance method included both stored soil moisture and rainfall during growing season and hence the ratio $\mathrm{AE} / \mathrm{PE}$ which indicates the rate at which water is supplied to the crop compared to its demand has been considered as an index of water availability to crops grown under rained condition (Virmani, 1975; Ramana Rao et al., 1979b). An attempt has been made in this paper to evaluate climatic risks associated with rainfed crop production under water stressed environment and thereby to suggest suitable crops and cropping sequence in NorthWest Alluvial Plains (Zone I) of Bihar for sustainable rainfed crop production based on Index of Moisture Adequacy.

\section{MATERIALS AND METHODS}

In this study, climatic risk for fitting of rainfed crops during kharif and rabi seasons has been worked out by employing the probabilistic values of $\mathrm{AE} / \mathrm{PE}$, i.e. index of moisture adequacy $\left(\mathrm{I}_{\mathrm{ma}}\right)$, estimated at 50 and 75 per cent probability levels on weekly basis. The weekly values of $I_{m a}$ was worked out through water balance method of Thorthwaite and Mather (1955) using historical weekly rainfall, normal weekly $\mathrm{PE}$ and available water holding capacity (AWC) of coarse-, medium- and fine-textured soils (Table 1). PE was calculated using PE Calculator software (V 3.0) developed by Central Research Institute for Dryland Agriculture, ICAR, Hyderabad (Bapuji Rao et al., 2012). Monthly PE data were converted into weekly total values by interpolation method as followed by Ramana Rao et al. (1979b). AWC of soil was estimated considering the layer 
wise soil textural classes up to one meter soil depth for each soil series. As reported by National Bureau of Soil Survey and Land Use Planning (NBSS \& LUP), Indian Council of Agricultural Research(ICAR), Nagpur, all soil series falling under each district were considered to calculate the water holding capacity for coarse-, medium- and fine-textured soils of individual district following the procedure of Saxton and Rawls (2006) and Saxton (2014). AWC per meter depth was calculated as the difference between field capacity and permanent wilting point.

Since the ratio AE/PE represents the rate at which water is supplied compared to the demand of water, it has been used as an index of crop water availability and for assessing the climatic risk associated with growing of rainfed crops in a region (Virmani, 1975; Ramana Rao et al., 1979b; Dey, 2008). The most important kharif and rabi crops grown under rainfed condition have been considered for this analysis in coarse-, medium- and fine-textured soils over different districts in Bihar. Rice and maize during kharif season, and toria and lentil during rabi season have been considered for this study. The optimal requirements of AE/ PE (bar) for different growth stages of transplanted rice, kharif maize, toria and lentil have been superimposed in the water availability diagrams in terms of $\mathrm{AE} / \mathrm{PE}$ (line) estimated at 50 and 75 per cent probability levels under medium textured soil, which is the dominant soil type in the region. The degree of water stress in coarse- and fine-textured soils have also been worked out based on values of AE/PE. The optimum water requirements in terms of $\mathrm{AE} / \mathrm{PE}$ for vegetative, reproductive and maturity stages of transplanted rice were considered as 1.0, 1.0 and 0.75, respectively (Doorenbos and Pruitt, 1977; Patel et al., 1986). For rainfed crops, such as kharif maize, toria, lentil, the optimum water requirement values for seedling, vegetative, reproductive and maturity stages were taken as $0.33,0.50,0.75$ and 0.33 , respectively (Ramana Rao et al., 1979b). As rice is also grown widely under rainfed condition, fitting of long, medium and shortduration varieties of rice in the cropping system has been considered. Different possible crop sequences under coarse, medium- and fine-textured soils were considered and based on the fitting analysis, the best fit crop and the best fit crop sequence have been identified. Ideal transplanting time of rice crop was considered one week after that week when $200 \mathrm{~mm}$ rainfall was accumulated at 50 per cent probability level (Dey, 2008). The sowing of kharif maize was considered in a week when $20 \mathrm{~mm}$ rainfall in a week was recorded at 50 per cent probability level (Ramana Rao et al., 1979b). 


\section{RESULTS AND DISCUSSION}

\section{Length of growing period}

Year-wise lengths of growing period (LGPs) were computed based on weekly values of index of moisture adequacy $\left(\mathrm{I}_{\mathrm{ma}}\right)$, from which mean LGP of different soils over different districts have been worked out (Table 1), which revealed that in coarse-textured soil, the mean LGPs were $144 \pm 17,175 \pm 31$ and $141 \pm 19$ days, whereas in medium-textured soil, they were $189 \pm 32,226 \pm 43$ and $164 \pm 33$ days in Muzaffarpur, West Champaran and Begusarai districts, respectively. In case of fine-textured soil, the estimated LGPs were $214 \pm 33,272 \pm 45$ and $185 \pm 38$ days in Muzaffarpur, West Champaran and Begusarai districts, respectively. West Champaran district recorded the longest LGP ranging from 175 days in coarse-textured soil to 272 days in fine-textured soil, followed by Muzaffarpur district having LGPs extending from 144 days in coarse-textured soil to 214 days in finetextured soil. The shortest LGP, exhibited by Begusarai district, varied from 141 days in coarse-textured soil to 185 days in fine-textured soil. Thus in terms of LGPs, the West Champaran district seems to be the most productive district followed by Muzaffarpur and Begusarai districts for rainfed crop production. The amount and distribution of rainfall, moisture storage in the soil profile and actual evapotranspiration determine the length of growing period in any given region (Kokilavani et al., 2012). Accordingly farmers should grow crop varieties according to length of water availability periods in their areas, which would help produce at potential rate and reduce the chances of crop failure due to moisture stress, leading to agricultural sustainability and food security in the vulnerable rainfed agro-ecosystem.

All types of soils under study in West Champaran district having mean LGPs ranging from 175 to 272 days are favourable for double cropping. On the other hand, mediumtextured soil with mean LGP of 189 days and fine-textured soil with mean LGP of 214 days in Muzaffarpur district and fine-textured soil of Begusarai district with mean LGP of 185 days are also suitable for double cropping with short duration varieties of rice and maize during kharif season and toria in the rabi season under rainfed condition. Contrarily, the coarse-textured soil with mean LGP of 164 days in Begusarai district seems to be suitable for mono-cropping only during kharif season or intercropping with short duration rice/ maize with pigeon pea in upland situation. Araya (2005) reported that a difference of 10-20 days in LGP produces differences not only in yield but also in the farmers' choice of crops and crop varieties.

\section{Water stress experienced by different crops in the cropping systems}

Compared to other crops, maize grown in kharif season does not experience water stress in any soils and districts (Table 2). Short duration rice endures slight water stress in all the soils in Muzaffarpur and West Champaran districts. Medium and long duration rice grown in mediumand fine-textured soils encounters slight water stress in Muzaffarpur district. Short, medium and long duration rice grown in fine textured soil in West Champaran district confront with slight water stress, while short and medium duration rice undergo water stress in all the soils in Begusarai district.

In case of rabi season, in Muzaffarpur district, toria undergoes water stress at vegetative, reproductive and maturity phases in coarse- and medium-textured soils and at reproductive phase in fine-textured soil only (Table 2). Lentil encounters water stress at vegetative, reproductive and maturity phases in all the soils under study. In coarsetextured soil, both toria and lentil face water stress during vegetative, reproductive and maturity phases during which $\mathrm{AE} / \mathrm{PE}$ values remain below 0.25 , whereas in medium-textured soil, toria experiences moderate drought $(0.50>\mathrm{AE} / \mathrm{PE}>0.25)$ and lentil confronts with severe drought $(\mathrm{AE} / \mathrm{PE}<0.25)$. Krishnan et al. (1980) defined moderate drought when AE/ $P E$ ratio was less than 0.50 and equals to or more than 0.25 $(0.50>\mathrm{AE} / \mathrm{PE}>0.25)$, severe drought when $\mathrm{AE} / \mathrm{PE}$ ratio was less than $0.25(\mathrm{AE} / \mathrm{PE}<0.25)$ and drought free growing period when $\mathrm{AE} / \mathrm{PE}$ ratio was equals to or greater than 0.50 $(\mathrm{AE} / \mathrm{PE}>0.50)$.

In West Champaran District, toria experiences slight water stress at reproductive phases in medium- and finetextured soils (Table 2). Lentil encounters water stress at vegetative, reproductive and maturity phases in coarseand medium-textured soils and at reproductive stage in finetextured soil. Toria experiences moderate drought and lentil confronts with severe drought when grown after maize and short duration rice in coarse-textured soil, while in mediumtextured soil, toria passes through drought free period when grown after maize and experiences moderate drought when grown after short duration rice. When grown in fine textured soil in West Champaran district, toria grows under drought free period. On the other hand, lentil undergoes severe drought when grown in coarse-textured soil and moderate drought in medium- and fine-textured soils. 


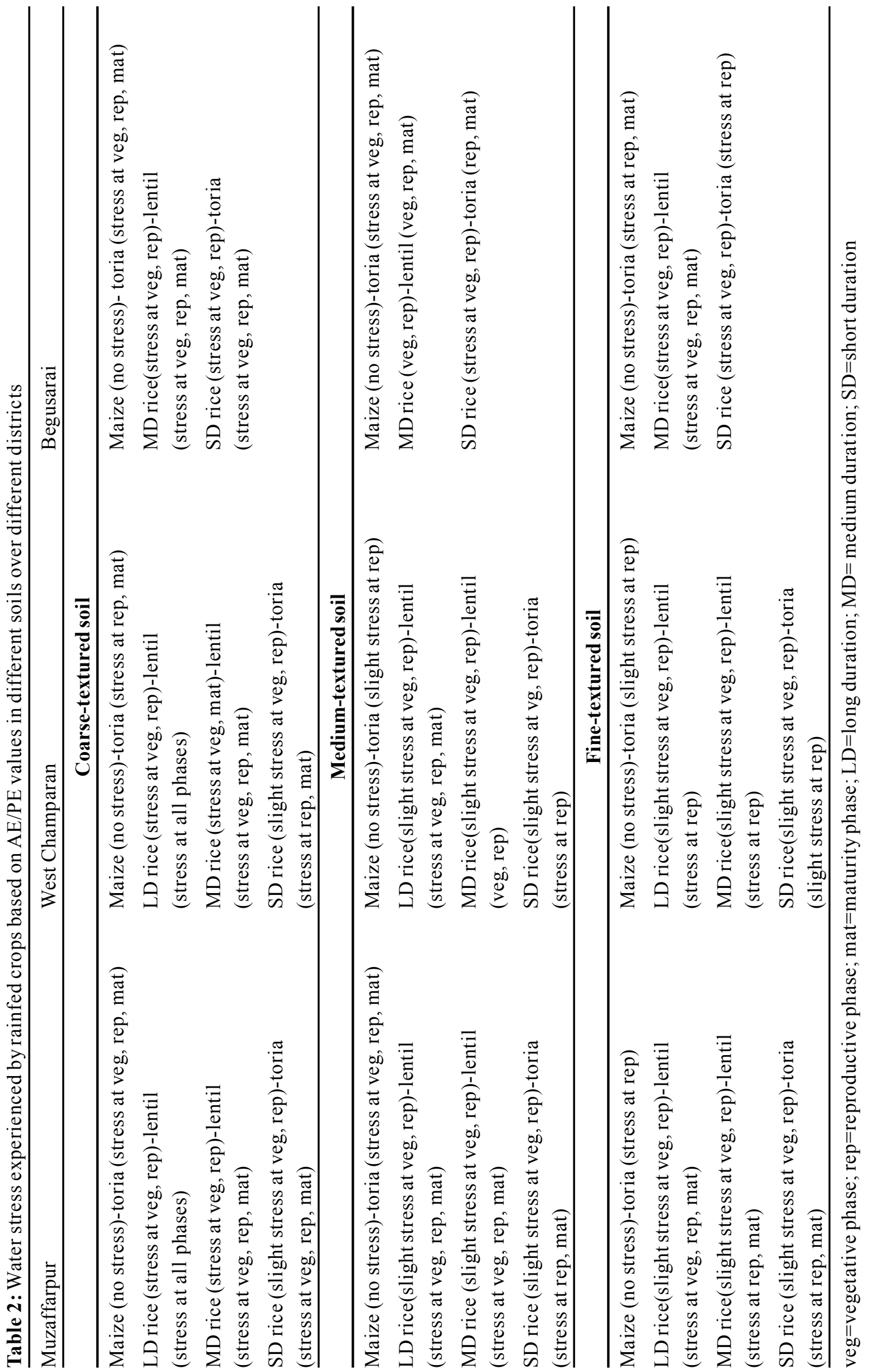



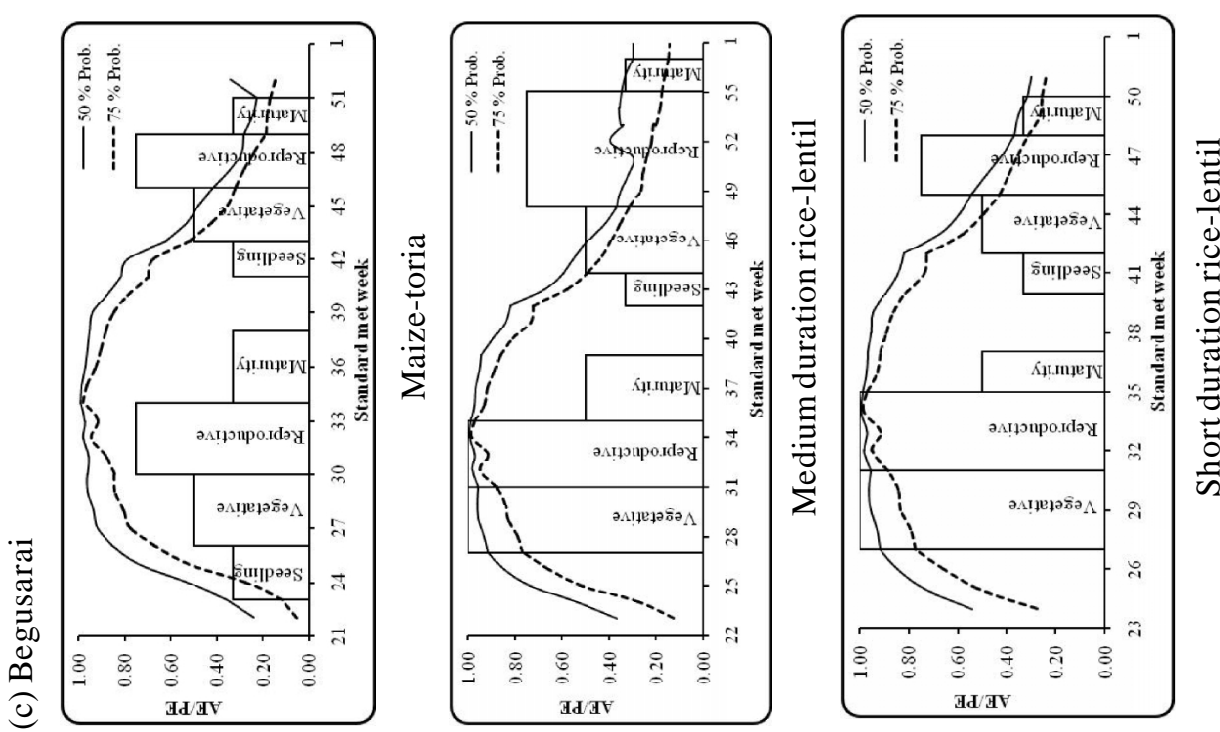

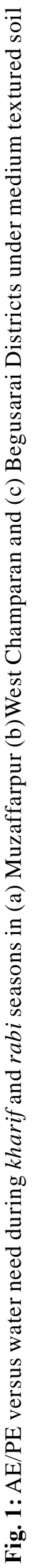
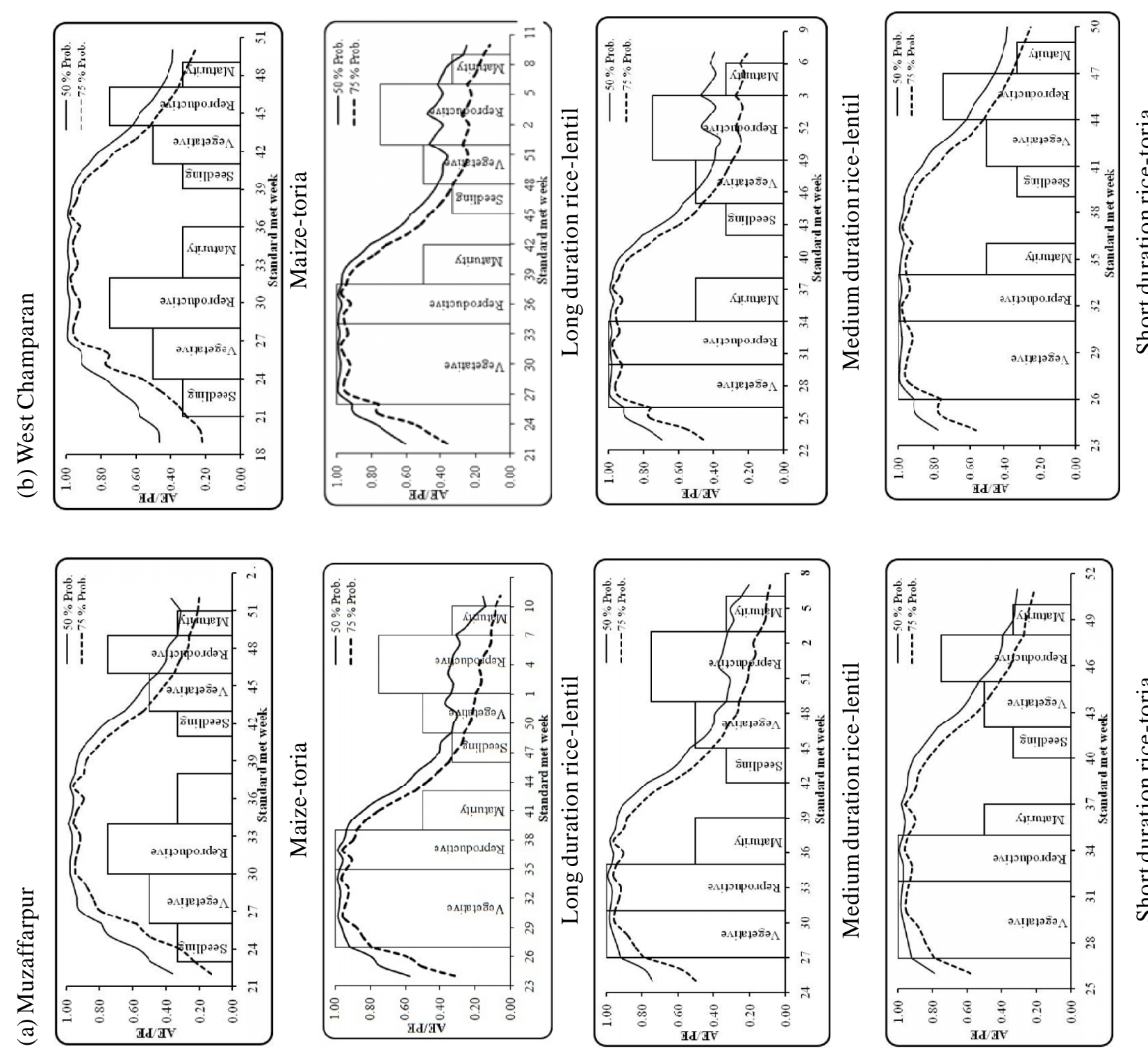
In Begusarai district, toria suffers from water stress in coarse- and medium-textured soils at vegetative, reproductive and maturity phases and at reproductive and maturity phases in fine-textured soil (Table 2). Lentil undergoes water stress in all the soils under study. Both lentil and toria confront with severe drought in coarsetextured soil and moderate drought when grown in mediumand fine-textured soils. In coarse textured soil, maize/short duration rice followed by toria seems to be the best cropping system under rainfed condition in all the districts. Changes in sowing of crop with early maturing varieties offer scope for enhancing crop production under rainfed condition (Krishnan, 1983).

\section{Water availability diagram of crops in medium textured soil}

Medium textured soil is the dominant soil type in all the districts under study. Accordingly, water availability diagrams of dominant crops viz. rice and maize during kharif season and lentil and toria during rabi season have been drawn for medium textured soil (Fig. 1). The diagrams (Fig. 1) reveal that water stress was not noticed during different growth phases of maize crop when maize and toria were considered as kharif and rabi crops, respectively. As all the growth phases of maize undergo drought free period (AE/ $\mathrm{PE}$ ratio $>0.50$ ), maize appears to be the most suitable kharif crop under rainfed condition. The seedling stage of toria crop also escaped water stress at both 50 and 75 per cent probability levels. However, subsequent toria crop was found to experience water stress during vegetative, reproductive and maturity phases with the maximum stress being observed during reproductive stage (Fig. 1). The level of water stress in toria was observed to be the highest in Begusarai, followed by Muzaffarpur district. Rabi crop in West Champaran district, located at the extreme north-west part of the state, experienced comparatively lower moisture stress. Besides maize, which encounters no water stress during its entire growth period, fair yields of rice could also be expected in medium textured soil. Ramana Rao et al. (1979a) estimated the probabilities of AE/PE ratio for identifying suitable kharif and rabi crops for different soils of the Gulbarga region of Karnataka. Stewart and Hash (1982) evaluated the suitability of a given crop for a semiarid location in Kenya using a water balance approach. With increase in duration of previous kharif crops, the effective growing period for subsequent rabi crops are shortened and they are subjected to drought of greater intensity and periodicity. As the results of the study identify water stress at various phases of growth, it can be used for scheduling supplemental irrigation.

\section{Alternate crops}

Usually farmers resort to cultivation of long duration rice in the kharif season and lentil, mustard and chick pea in the succeeding rabi season. Due to longer duration, these crops are subjected to moisture stress at different stages of growth and hence they are vulnerable to produce less which is evident from the water availability diagrams (Fig. 1). The results emanated from the study shows that the most appropriate alternate crops under rainfed condition are maize and toria. Maize during kharif season and toria during rabi season have higher potential in all the districts. Another promising kharif crop is groundnut which could be profitably grown in the upland situation. Short duration rice matching favourably with water availability period has greater prospect in Muzaffarpur and West Champaran districts. Rice during kharif season should be avoided in Begusarai district due to possibility of greater moisture stress at all growth phases.

While considering alternate crops, instead of mono cropping, inter cropping should be prioritized. The results indicated that adoption of double cropping under rainfed condition could be feasible in medium and fine textured soils. Emphasis should be given for selection of appropriate short duration varieties for making the sequential cropping during kharif and rabi seasons more successful. As compared to pigeon pea as sole crop, cultivation of direct seeded short duration rice and maize in kharif season followed by improved short duration varieties of the subsequent crops in the rabi season is required to ensure the successful sequential cropping. Short duration varieties of rabi oil seeds and pulses could be grown in medium and fine textured soils with greater success after the harvest of short duration kharif crops. Intercropping pigeon pea sown in $50 \mathrm{~cm}$ apart rows along with one row of maize or turmeric in between pigeon pea followed by green gram in the summer season with supplemental irrigation has been proved to be remunerative practice. Crops like soybean and black gram hold promising in Begusarai and Muzaffarpur districts under rainfed condition, while maize/short duration rice followed by rabi vegetables could be an alternative option in West Champaran district.

\section{CONCLUSION}

Appropriate rainfed crops have been identified for coarse-, medium- and fine-textured soils in three districts of 
Bihar in comparison with $\mathrm{AE} / \mathrm{PE}$ estimated at 50 and 75 per cent probability levels and water need of crops at different pheno-phases. The potential yield of maize could be achieved with good agronomic practices during kharif season under rainfed condition instead of rice. The results of the study also allowed for substituting the long duration rice crop with short duration one and maize followed by toria/rapeseed depending upon agro-climatic conditions. The study identifies water stress at various phases of growth, so it has practical utility for scheduling irrigation. Alternate crops such as soybean, turmeric as intercrop could be introduced in the area under rainfed condition.

\section{REFERENCES}

Araya, A. (2005) An agro-climatic characterization towards improving barley production in the Giba catchment, Northern Ethiopia. MSc dissertation. MAGM program. University ofZimbabwe, Harare, Zimbabwe, pp132.

Bapuji Rao, B., Rao, V.U.M., Sandeep, V.M., Shanthibhushan Chowdary, P. and Venkateswarlu, B. (2012). PET Calculator(V.3.0). All India Coordinated Research Project on Agrometeorology, Central Research Institute for Dryland Agriculture, Hyderabad-500059, A.P., India.

Dey, S. (2008). An agroclimatic assessment of water availability for crop planning in the plains of West Bengal. Ph.D. thesis. Department of Agril. Meteorology \& Physics, BCKV, Mohanpur.

Doorenbos, J. and Pruitt, W. O. (1977). Guidelines for predicting crop water requirements. FAO irrigation and drainage paper No. 24 (revised) FAO. Rome. 144 pp.

Kokilavani, S., Geethalaksmi, V., Arthirani,B. and Natarajan, S.K. (2012). Variability of length of growing period in Coimbatore district. J. Agrometeorol. 14:368-371.

Krishnan,A., Ramakrishna, Y. S. and Sastry, A.S.R.A.S. (1980). System analysis for crop planning in Jodhpur district. Indian J. Agric. Sci. 50(5): 412-21
Krishnan,A. (1983). Use of water balance approach for appraisal of double cropping and estimation of surplus water for harvesting in semi-aridBangalore region. Proceeding of Symposium on Water Balance and Natural Development,19-21 December, 1983, A.U., Waltair, 143148.

Misra, A.K. (2005). Contingency planning for feeding and management of livestock during drought. In: Drought Management, eds: K.D. Sharma and K.S. Ramasastri, Allied Publishers Pvt. Ltd., New Delhi. pp. 276-286.

Patel, S.R., Sastri, A.S.R.A.S., Gupta, V.K. and Chandravanshi, B.R. (1986). Crop yields as influenced by agricultural drought- A water balance approach. Mausam. 37(3): $341-342$.

Ramana Rao, B.V., Biradar, B.R., Surpur, S.S. and Rao, M.G. (1979a). A climatological study on water avialbility to crops in different types of soils in Gulbarga region. $J$. Indian Soc. Soil Sci., 27:441-445.

Ramana Rao, B.V., Biradar, B.R., Surpur, S.S., Rao, M.G. and Satyanarayana, T. (1979b). Astudy on water availability to the crops grown under rainfed conditions in different soils at Bijapur. Mausam. 30(4):469-472.

Saxton K,E. and Rawls, W.J. (2006). Soil water characteristic estimates by texture and organic matter for hydrologic solutions. SoilSci. Soc. Am. J., 70: 1569-1578.

Saxton, K.E. (2014). Personal communication.

Stewart, J.I. and Hash, C.T. (1982). Impact of weather analysis on agriculture production and planning decisions for the semiarid areas of Kenya. Appl. Meteorol. 21:477494.

Thornthwaite, C.W. and Mather, J.R. (1955).The water balance: Publication in Climatology, Drexel Institute of Technology, New Jersey, 8: 1-104.

Virmani, S.M. (1975). The agricultural climate of Hyderabad region in relation to crop planning, Technical Report, ICRISAT, pp. 54. 